\title{
Estimates of Genetic Parameters for Single- and Multiple-Country Test-Day Models
}

\author{
J. Jamrozik, ${ }^{*}$ L. R. Schaeffer, ${ }^{*}$ and K. A. Weigel \\ ${ }^{*}$ Centre for Genetic Improvement of Livestock \\ Department of Animal and Poultry Science \\ University of Guelph \\ Guelph, ON, N1G 2W1, Canada \\ Department of Dairy Science \\ University of Wisconsin \\ Madison, WI 53706, USA
}

\begin{abstract}
Single- and multiple-country random regression models were applied to estimate genetic parameters for first-lactation test-day milk yield of cows from four countries: Australia, Canada, Italy, and New Zealand. Selected countries represented a wide range of production systems and environments. Milk production in Canada and Italy is based mainly on intensive management systems, while Australia and New Zealand are largely based on rotational grazing. Legendre polynomials with five coefficients were used to model genetic and environmental lactation curves. Covariance components of lactation curve coefficients within and across countries, and selected functions of those, were estimated by Bayesian methods with Gibbs sampling, on selected subsets of data. Countries differed in both phenotypic and genetic parameters of lactation curves between d 5 and 305 of lactation. Principal component analysis of single-trait genetic and environmental covariance matrices showed, however, that the pattern of variability in test-day milk yield was very similar between countries. General level of milk production in lactation and persistency components accounted for more than $90 \%$ of the total variance. Estimated genetic correlations between countries for total yield in lactation ranged from 0.65 (Italy and New Zealand) to 0.83 (Australia and New Zealand), indicating a possibility of genotype by environment interaction for some pairs of countries.
\end{abstract}

(Key words: international evaluation, test-day model, multiple trait, genetic parameter)

Abbreviation key: INTERBULL = International Bull Evaluation Service, MACE = multiple-trait, across-

Received December 3, 2001.

Accepted February 10, 2002.

Corresponding author: J. Jamrozik; e-mail: jamrozik@sherlock. aps.uoguelph.ca. country evaluation, $\mathbf{T D}=$ test-day, $\mathbf{P E}=$ permanent environment.

\section{INTRODUCTION}

International evaluation of dairy sires conducted by the International Bull Evaluation Service (INTERBULL) is a two-step procedure. First, withincountry EBV are estimated. Then, they are combined by the multiple-trait, across-country evaluation (MACE) method (Schaeffer, 1994) under a multiple-trait sire model, where progeny performances in different countries are considered as genetically different traits. International indices might be influenced by several factors, including within-country methods of data recording and models for calculating EBV. No direct estimates of across-country cow breeding values are available. Genetic correlations between countries have been estimated by an approximate REML method with deregressed sire EBV as input data (Sigurdsson et al., 1996).

A research project using individual animal performance records for international comparison originated in 2000. Data from 17 countries were used to estimate genetic parameters from a multiple-trait sire model, and lactation yields were analyzed in a multiple-trait sire model for the purpose of international genetic evaluation (Weigel et al., 2001).

Test-day (TD) models have been applied by several countries for genetic evaluation of dairy production traits (INTERBULL, 2000). Accounting for the shape of an animal's lactation curve through regressions and modeling short-term environmental effects provide more accurate genetic evaluations for cows (4 to 8\%) and bulls (2 to 5\%) over evaluations from 305 -d yields (Kistemaker, 1997). Despite computational difficulties associated with multiple-trait TD models, prospects exist for applying this methodology for international genetic evaluation of animals. 
Table 1. Data characteristics (as received from respective countries). Country codes are: AUS = Australia, $\mathrm{CAN}=$ Canada, ITA $=$ Italy, NZL = New Zealand .

\begin{tabular}{lcccc}
\hline & AUS & CAN & ITA & NZL \\
\hline TD $^{1}$ records & $7,803,696$ & $8,839,030$ & $12,608,858$ & $6,022,272$ \\
Cows & 945,798 & $1,075,516$ & $1,422,605$ & $1,560,268$ \\
Herds & 9706 & 14,486 & 17,679 & 18,454 \\
Test days & 3271 & 3210 & 3277 & 2633 \\
Cows/herd & 97.4 & 74.2 & 80.5 & 84.5 \\
TD Records/cow & 7.7 & 8.2 & 8.9 & 3.9 \\
\% Supervised records & 19 & 72 & 99 & 11 \\
Yield at DIM 60 (kg) & 20.2 & 27.5 & 27.2 & 16.8 \\
Yield at Dim 280 (kg) & 12.1 & 19.3 & 21.1 & 9.8 \\
DIM at peak yield & 38 & 46 & 55 & 32 \\
Peak yield (kg) & 20.6 & 27.7 & 27.8 & 17.7 \\
\hline
\end{tabular}

${ }^{1} \mathrm{TD}=$ Test-day

The objective of this study was to estimate covariance components and genetic parameters for both singleand multiple-trait test-day models for four selected countries: Australia, Canada, Italy, and New Zealand. Between-country genetic correlations of lactation curve parameters can be an indicator of genotype $\times$ environment interactions for the shape of lactation curve. Multiple-trait estimates of covariance components can be used to rank animals internationally, using a multiplecountry TD model.

\section{MATERIAL AND METHODS}

\section{Data}

Data were first-lactation TD milk yield $(\mathrm{kg})$ records from four countries: Australia, Canada, Italy, and New Zealand. Countries were selected based on relatively small data sizes and a wide range of production systems and environments represented. Only milk yield in first lactation was analyzed. Cows of Holstein sires calving between January 1, 1990, and December 31, 1997, were included. The number of TD records, cows, herds, and other descriptive characteristics of the original data (before edits) from four countries are shown in Table 1. Average phenotypic lactation curves from 5 to 305 DIM by country are in Figure 1.

Countries differed in many aspects of their dairy production systems (Table 1). Population sizes ranged from 0.9 million (Australia) to 1.6 million (New Zealand) first-lactation cows, while average herd size ranged from 74 cows (Canada) to 97 cows (Australia). Average number of TD records per cow was smallest for New Zealand (3.9) and largest for Italy (8.9). Almost 100\% of Italian TD records came from supervised testing schemes, while only 11 and $19 \%$ were supervised in New Zealand and Australia, respectively. Italy and Canada had the highest level of daily milk production, followed by Australia and New Zealand. Sizable differ- ences between persistency of lactation, measured as a difference in yields on DIM 280 and 60, existed between countries, with Italy having the most persistent overall lactation curve. Atypical shapes of Australian and New Zealand lactation curves late in the lactation (DIM $>270$ ) were attributed to differences in average length of lactation and smaller number of TD records in this interval. More detailed characteristics of dairy production systems in analyzed countries was given by Zwald et al. (2001).

Number of sires of cows with data (Table 2) ranged from 3000 (New Zealand) to over 22,000 (Italy). Only 173 sires had progeny in all four countries. This group of bulls included 113 sires with US registration numbers, 57 Canadian bulls, and three sires with the Netherlands as the country code in the registration number. Genetic links (through common sires) between countries (Table 3) were strongest between Canada and Aus-

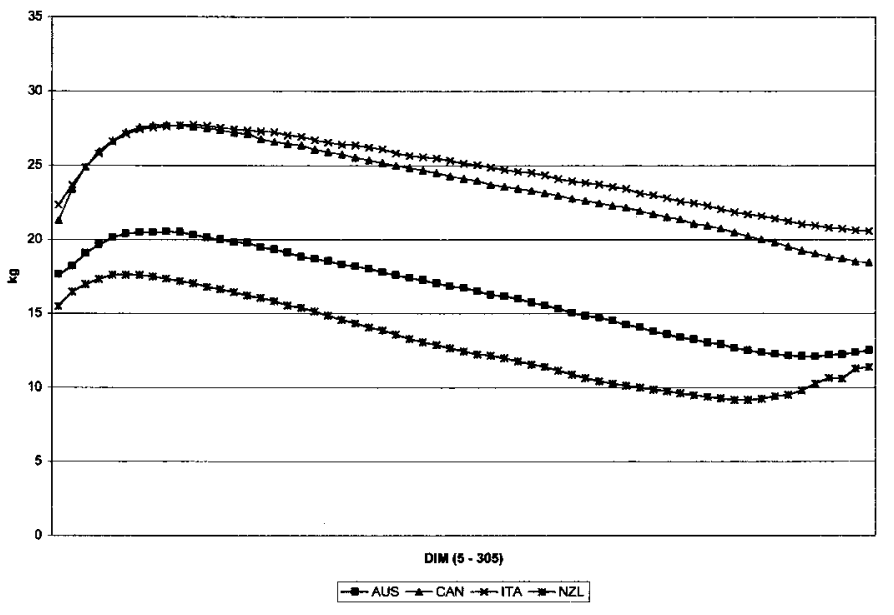

Figure 1. Plot of average daily milk yields $(\mathrm{kg})$ of first-lactation cows from Australia, Canada, Italy, and New Zealand (overall dataset). Country codes are: AUS = Australia, $\mathrm{CAN}=$ Canada, ITA = Italy, NZL = New Zealand 
Table 2. Distribution of sires (of cows with test-day records) across countries. Country codes are: AUS = Australia, CAN = Canada, ITA = Italy, NZL = New Zealand.

\begin{tabular}{lllll}
\hline & \multicolumn{4}{c}{ No. of sires with daughters } \\
\cline { 2 - 5 } Data origin & 1 country & 2 countries & 3 countries & 4 countries \\
\hline AUS & 13,869 & 616 & 225 & 173 \\
CAN & 15,337 & 625 & 248 & 173 \\
ITA & 22,416 & 313 & 145 & 173 \\
NZL & 3007 & 428 & 159 & 173 \\
\hline
\end{tabular}

tralia, with 657 common sires, and the weakest between Italy and New Zealand, with 238 common sires. Overall edits on TD records included: DIM between 5 and 305 $\mathrm{d}$, age at calving between 18 and 38 mo., and daily milk yield between 0.1 and $100 \mathrm{~kg}$.

Pedigree data for bulls were from the official INTERBULL pedigree file. Cow pedigrees were provided by the respective countries, including data on sire, dam, maternal grandsire, and maternal granddam.

Estimation of covariance components for both singleand multiple-trait random regression TD models required additional selection of data. The full dataset as described above could not be used for these purposes because of its size. Two subsets of the total data were created. Single-trait models were applied on data with rather weak genetic links between countries, and multiple-trait models required strong genetic ties between countries.

Single-Trait Models. The following steps were applied to select data for single-trait (within-country) parameter estimation:

1. A total of 50 sires with daughters in at least two countries were randomly selected for each country;

2. a total of 100 herds for Australia and Italy, and 150 herds for Canada and New Zealand, with each herd containing at least one daughter of one of the 50 selected sires were chosen;

3. all records on cows in the selected herds were kept for within-country analyses.

Characteristics of selected datasets are shown in Table 4. BSA was defined as a joint subclass for breed composition ( $100 \%$ Holstein or $<100 \%$ Holstein, for Australia and New Zealand cows only), season of calving (four seasons for Italy and two seasons for other countries), and age at calving class $(<26,26$ to 30 , and $>30$ mo). Plots of average lactation curves (by country) estimated from this reduced dataset are shown in Figure 2.

Multiple-Trait Model. Parameters for the multipletrait random regression TD model were estimated using a dataset created as follows:

1) Sires with daughters in all four countries (173 bulls) were selected.

2) Daughters of the 173 selected sires up to a maximum of 100 daughters per sire in a given country were kept.

3) Daughters of remaining sires, so that the total number of selected cows was between 14,000 and 15,000 per country, were added.

4) Records on dams (if any) of selected cows were added.

5) TD records in herd-TD classes with only one observation were deleted.

The resulting dataset (316,967 TD records on 51,489 cows) is characterized in Table 4. Plots of average lactation curves (by country), estimated from this data, are shown in Figure 3. Shapes of average lactation curves were very similar between datasets for each country (Figures 1,2, and 3). Because of smaller number of records per DIM, selected subset of data had less regular shapes of lactation curves compared with the overall curves. Cows selected for the single-trait estimation procedure had slightly higher levels of production compared with overall curve. Cows selected for the multiple-trait estimation had higher levels of production compared with single-trait datasets. Despite these differences, both selected subsets of data were assumed to be representative samples from the respective overall populations. New Zealand showed a sharp increase in average TD milk yield at the end of lactation. Only 6\% of TD records in this country were collected beyond 260

Table 3. Number of sires (of cows with test-day records) in other countries. Country codes are: AUS = Australia, CAN = Canada, ITA = Italy, NZL = New Zealand .

\begin{tabular}{lrrrr}
\hline Data origin & \multicolumn{1}{c}{ AUS } & CAN & ITA & NZL \\
\hline AUS & 13,869 & 657 & 303 & 625 \\
CAN & 657 & 15,227 & 581 & 402 \\
ITA & 303 & 581 & 22,416 & 238 \\
NZL & 625 & 402 & 238 & 3007 \\
\hline
\end{tabular}


Table 4. Data characteristics for single- and multiple-trait estimation. Country codes are: AUS = Australia, CAN $=$ Canada, ITA $=$ Italy, NZL $=$ New Zealand.$^{1}$

\begin{tabular}{lrrrr}
\hline & \multicolumn{1}{c}{ AUS } & CAN & ITA & NZL \\
\hline Single-trait model & & & & \\
TD records & 121,195 & 120,446 & 128,149 & 61,240 \\
Cows & 15,000 & 14,798 & 15,834 & 16,668 \\
Animals & 25,087 & 30,560 & 32,550 & 29,840 \\
Herds & 100 & 150 & 100 & 150 \\
HTD classes & 6107 & 12,239 & 9646 & 2487 \\
BSA classes & 9 & 6 & 12 & 6 \\
Multiple-trait model & & & & 74,938 \\
TD records & 91,469 & 57,765 & 92,795 & 123 \\
Cows & 12,805 & 9390 & 14,171 & 1682 \\
Herds & 1791 & 1911 & 1963 & 16,621 \\
HTD classes & 29,506 & 22,004 & 33,053 & \\
\hline
\end{tabular}

${ }^{1} \mathrm{TD}=$ Test-day; HTD = herd-TD; BSA = breed composition-age at calving-season of calving.

DIM, compared with 11,12 , and $11 \%$ for Australia, Canada, and Italy, respectively. Longer lactations in New Zealand data are usually from herds with superior management practices. Those herds have much higher levels of feeding in the second half of lactation (W. A. Montgomerie, personal communication).

\section{Models}

Single-Trait Models. The equation for the singletrait (within-country) linear model was:

$$
\begin{aligned}
\mathrm{Y}_{\mathrm{ijkt}}=\mathrm{HTD}_{\mathrm{i}} & +(\mathrm{BSA} \times \mathrm{DIM})_{\mathrm{j}}+\sum \mathrm{a}_{\mathrm{kl}} \mathrm{z}_{\mathrm{tl}} \\
& +\sum \mathrm{p}_{\mathrm{kl}} \mathrm{z}_{\mathrm{tl}}+\mathrm{e}_{\mathrm{ijkt}}
\end{aligned}
$$

where:

$$
\begin{aligned}
\mathrm{Y}_{\mathrm{ijkt}}= & \text { milk yield of cow } \mathrm{k} \text { made on day } \mathrm{t} \text { of } \\
& \text { lactation, within herd-test day effect } \\
& \mathrm{i} \text {, for a cow belonging to subclass } \mathrm{j} \\
& \text { for breed composition, age at calving, } \\
& \text { season of calving, and DIM interval } \\
(\mathrm{BSA} \times \mathrm{DIM})_{\mathrm{j}}= & \text { fixed breed composition, age at calv- } \\
& \text { ing, season of calving and DIM inter- } \\
& \text { val effect } \\
\mathrm{a}_{\mathrm{kl}}= & \text { random regression genetic coeffi- } \\
& \text { cients specific to cow } \mathrm{k} \\
\mathrm{p}_{\mathrm{kl}}= & \text { random regression coefficients for } \\
& \text { permanent environment }(\mathbf{P E}) \text { effect } \\
& \text { on cow } \mathrm{k} \\
\mathrm{e}_{\mathrm{ijkt}}= & \text { residual effect for each observation } \\
\mathrm{z}_{\mathrm{tl}}= & \text { covariates, assumed to be the same } \\
& \text { for genetic and PE regressions }
\end{aligned}
$$

Regression curves were modeled by Legendre polynomials of order four, i.e.,

$$
\begin{aligned}
& \mathrm{z}_{\mathrm{t} 0}=1.0 \\
& \mathrm{z}_{\mathrm{t} 1}=3.0^{0.5} \mathrm{x} \\
& \mathrm{z}_{\mathrm{t} 2}=5.0^{0.5}\left(1.5 \mathrm{x}^{2}-0.5\right) \\
& \mathrm{z}_{\mathrm{t} 3}=7.0^{0.5}\left(2.5 \mathrm{x}^{3}-1.5 \mathrm{x}\right) \\
& \mathrm{z}_{\mathrm{t} 4}=9.0^{0.5}\left(35 \mathrm{x}^{4}-30 \mathrm{x}^{2}+3\right) / 8
\end{aligned}
$$

where $\mathrm{x}=2(\mathrm{t}-5) / 300-1$ is a standardized (in interval from -1 to +1 ) time.

Twenty-nine DIM classes were formed as [5,20], [291,305], and 10-d intervals for DIM from 21 to 290. Classes were used in place of regressions to model fixed lactation curves. Residual variances were assumed to be constant within DIM intervals; all residual covariances were equal to zero.

Multiple-Trait Model. The multiple-trait (country) TD model combined the within-country models through an appropriate covariance structure between countries.

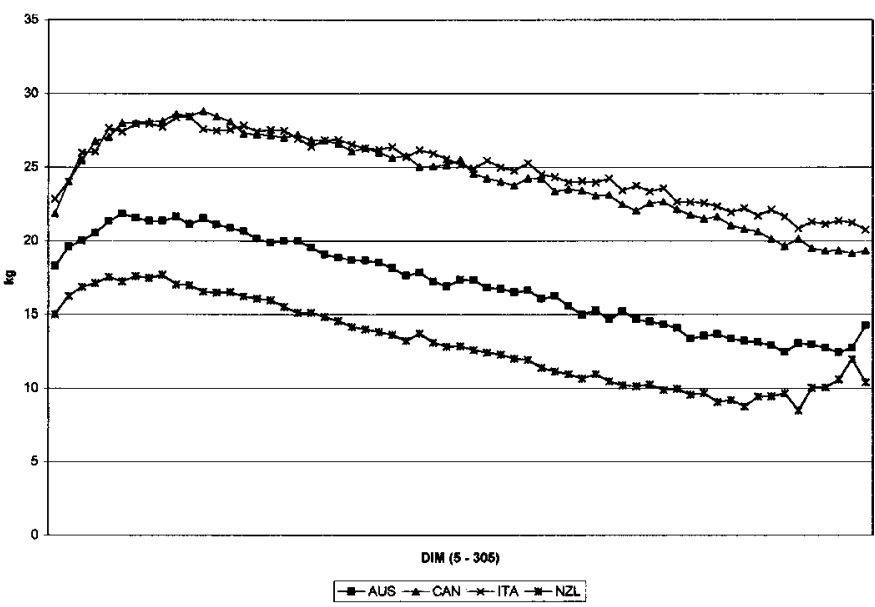

Figure 2. Plot of average daily milk yields (kg) of first-lactation cows from Australia, Canada, Italy, and New Zealand (dataset used for single-trait models). Country codes are: AUS = Australia, CAN = Canada, ITA = Italy, NZL = New Zealand. 
Models were assumed to be the same for each country, with possible differences in definition (number of levels) of fixed effects. In matrix notation, the multiple-trait model was:

$$
\mathbf{y}=\mathbf{H h}+\mathbf{X b}+\mathbf{W} \mathbf{p}+\mathbf{Z} \mathbf{a}+\mathbf{e}
$$

where

$\mathbf{y}=$ vector of observations on four traits defined as milk yield within country borders

$\mathbf{h}=$ vector of fixed contemporary group (HTD) effects (nested within countries)

$\mathbf{b}=$ vector of fixed BSA $\times$ DIM effects (nested within countries)

$\mathbf{p}=$ vector of random regression coefficients for PE effect

$\mathbf{a}=$ vector of random regression coefficients for animal genetic effect

$\mathbf{e}=$ vector of residual effects

$\mathbf{H}, \mathbf{X}, \mathbf{W}$, = incidence matrices assigning observations and $\mathbf{Z}$ to effects

Expectations and covariance matrices for random effects were:

$$
E\left[\begin{array}{c}
\mathbf{y} \\
\mathbf{p} \\
\mathbf{a} \\
\mathbf{e}
\end{array}\right]=\left[\begin{array}{c}
\mathbf{H h}+\mathbf{X b} \\
\mathbf{0} \\
\mathbf{0} \\
\mathbf{0}
\end{array}\right]
$$

and

$$
V\left[\begin{array}{c}
\mathbf{p} \\
\mathbf{a} \\
\mathbf{e}
\end{array}\right]=\left[\begin{array}{lll}
\mathbf{P} & \mathbf{0} & \mathbf{0} \\
\mathbf{0} & \mathbf{G} & \mathbf{0} \\
\mathbf{0} & \mathbf{0} & \mathbf{E}
\end{array}\right],
$$

where $\mathbf{P}=\mathbf{I} \otimes \mathbf{P}_{\mathbf{0}}, \mathbf{G}=\mathbf{A} \otimes \mathbf{G}_{\mathbf{0}} ; \mathbf{A}$ is an additive relationship matrix; $\mathbf{P}_{\mathbf{0}}$ (block-diagonal matrix) and $\mathbf{G}_{\mathbf{0}}$ are 20 $\times 20$ covariance matrices for environmental and genetic regression coefficients, respectively. Residual covariance matrix $\mathbf{E}$ can be written as $\operatorname{diag}\left(\mathrm{e}_{\mathrm{kt}}\right)$.

\section{Methods}

Bayesian methods with Gibbs sampling were used to estimate posterior means of covariance components and selected functions thereof for the single-trait models. Single chains of 55,000 samples (with 5000 discarded) were generated for each country model. Flat prior distributions were assumed for all fixed effects. For genetic and PE effects, normal prior distributions were used. Priors for covariances were as estimated previously from Canadian Holstein data (Jamrozik, unpublished data), with small numbers of degrees of freedom. Gibbs sampling employed conditional normal distributions for systematic effects, multivariate normal distributions for genetic and PE effects, and inverted Wishart and chi-square distributions for genetic and $\mathrm{PE}$ covariances, and residual variances, respectively. For the multipletrait model, a chain of 105,000 samples (with 10,000 as burn-in period) was generated. Similar distributional assumptions were made as for single-trait models. Preliminary estimates of covariance components based on the same data were taken as priors for multiple-trait analysis.

Convergence of Gibbs chains were monitored by inspecting plots of selected realizations. Average effective sample size of genetic variance and covariance components for single-trait models ranged from 76 (New Zealand) to 104 (Canada). Average number of independent genetic components was equal to 20 for the multiple-country model. The $\mathrm{PE}$ and residual components had larger effective sample sizes for both single- and multiple-country models. Heritabilities of the Legendre parameters, and genetic and PE correlations between those parameters were estimated. Principal component analyses were performed on estimates of genetic and $\mathrm{PE}$ covariances. Values of genetic (PE) eigenfunctions were calculated as $\sum c_{\mathrm{tj}} z_{\mathrm{tj}}$ in the interval from 5 to 305 DIM, where $c_{i j}$ is the jth element of the ith eigenvector of genetic (PE) covariance matrix.

Due to the orthogonal properties of Legendre polynomials, BV for the total yield in lactation (defined as sum of daily yields between DIM 5 and 305) of the ith animal is easily calculated as $301 \times B V\left(a_{i 0}\right)$, while

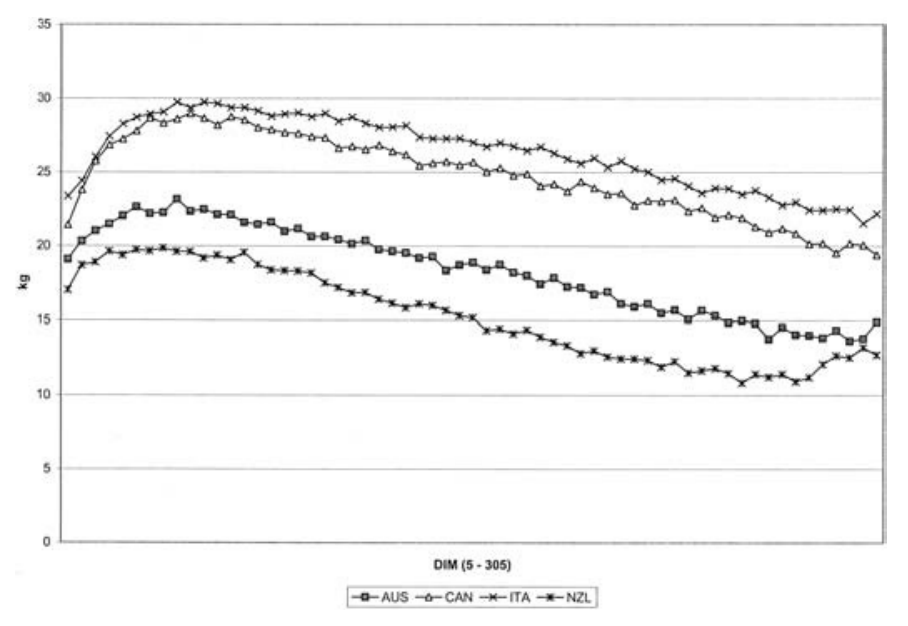

Figure 3. Plot of average daily milk yields (kg) of first-lactation cows from Australia, Canada, Italy, and New Zealand (dataset used for multiple-trait model). Country codes are: AUS = Australia, CAN $=$ Canada, ITA = Italy, NZL = New Zealand. 


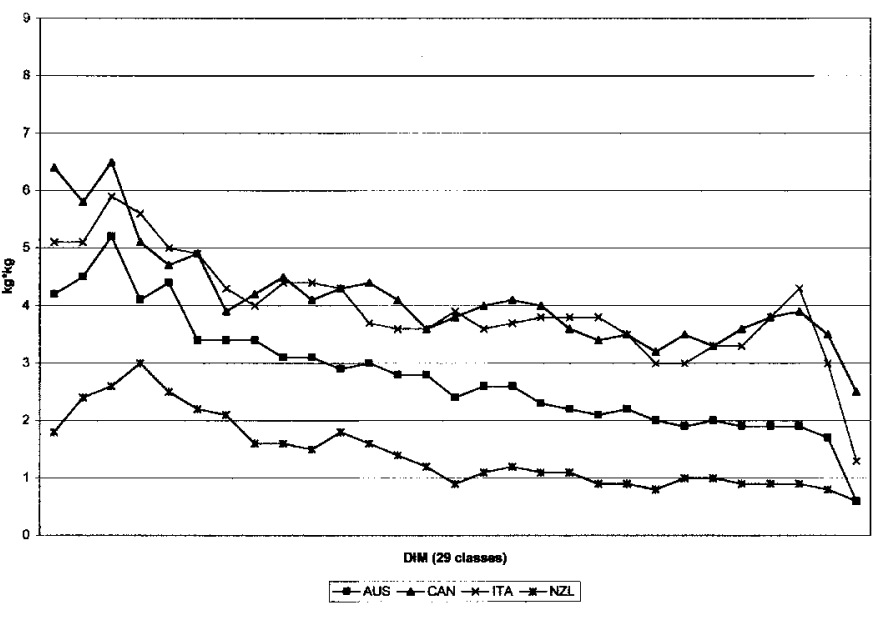

Figure 4. Estimates of residual variance $\left(\mathrm{kg}^{2}\right)$ of daily first-lactation milk yield from Australia, Canada, Italy, and New Zealand (single-trait models). Country codes are: AUS = Australia, CAN = Canada, ITA $=$ Italy, NZL = New Zealand .

the genetic variance of the total yield can be expressed as $301^{2} \times \operatorname{var}\left(\mathrm{a}_{\mathrm{i} 0}\right)$. Between-country genetic correlations for total yields are the same as respective correlations for the genetic intercept $\left(a_{0}\right)$.

\section{RESULTS}

\section{Residual Variances}

Plots of estimated residual variances from single- and multiple-trait models are shown in Figures 4 and 5, respectively. General level of residual variance followed the pattern of average lactation curves (Figures 1, 2,

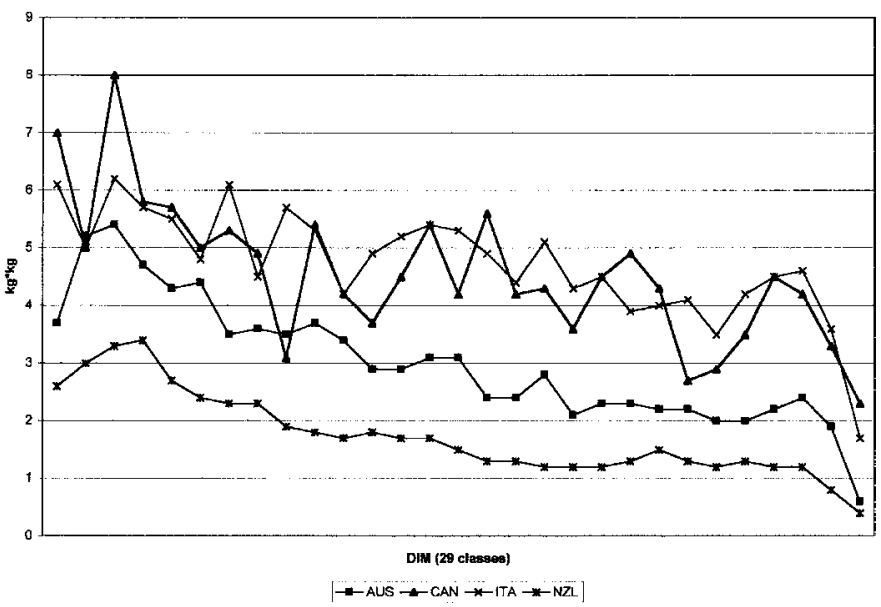

Figure 5. Estimates of residual variance $\left(\mathrm{kg}^{2}\right)$ of daily first-lactation milk yield from Australia, Canada, Italy, and New Zealand (multiple-trait model). Country codes are: AUS = Australia, CAN = Canada, ITA = Italy, NZL = New Zealand. and 3) for selected countries. Italy and Canada had the highest values of residual variances, followed by Australia and New Zealand. Both models showed a clear heterogenity in residual variance, with the highest values centered around the peak of lactation and the smallest at the end of lactation. Differences between single- and multiple-trait estimates were small, with slightly higher degree of irregularity in residual variance curves for multiple-trait model.

\section{Genetic and PE Covariance Components}

Posterior means of single- and multiple-trait estimates of variance for genetic random regression coefficients are shown in Table 5. Canada and Italy showed the highest variability of variances for all parameters, with New Zealand having the lowest values of estimates. This corresponds with the overall level of variation in phenotypes for the analyzed countries. Multipletrait estimates were in relatively good agreement with corresponding single-trait values. An increase in the variance of the intercept over single-trait estimates could be observed for Australia, Italy, and New Zealand. Variances of other terms generally decreased in comparison with single-trait estimates.

Posterior means of single- and multiple-trait estimates of variance for PE regression coefficients (Table 6) showed similar characteristics. Variation of PE intercept $\left(\mathrm{a}_{0}\right)$ was larger than the variance of its genetic counterpart, for all four countries.

\section{Genetic Parameters of Lactation Curves}

Single-trait genetic parameters of lactation curve coefficients are shown in Table 7. Heritabilities were moderate to high, with $\mathrm{h}^{2}$ for the intercept (which is also $\mathrm{h}^{2}$ for the total yield in lactation) ranging from 0.41 for Italy to 0.47 for Canada and New Zealand. The linear term $\left(\mathrm{a}_{1}\right)$ had the largest heritability in Canada and New Zealand. Genetic and PE correlations between curve parameters were small, with $\mathrm{PE}$ correlations lower than genetic correlations. Australia and New Zealand showed opposite genetic relationships between $\mathrm{a}_{0}$ and $\mathrm{a}_{1}$ than Canada and Italy.

Posterior means of genetic parameters for lactation curve parameters from multiple-trait model are presented in Table 8. Multiple-trait model increased the heritability of the intercept for Australia, decreased for Canada, and gave the same estimates as the singletrait model for Italy and New Zealand. Heritabilities of the linear term decreased to a larger extent for all four countries. Multiple-trait genetic and PE correlations between lactation curve coefficients generally followed the pattern of corresponding single-trait estimates. 
Table 5. Posterior means (SD in parenthesis) of single- and multiple-trait estimates of variances of genetic random regression coefficients. Country codes are: AUS $=$ Australia, CAN $=$ Canada, ITA $=$ Italy, NZL $=$ New Zealand.

\begin{tabular}{|c|c|c|c|c|c|c|}
\hline & Country & $\mathrm{a}_{0}$ & $\mathrm{a}_{1}$ & $\mathrm{a}_{2}$ & $\mathrm{a}_{3}$ & $\mathrm{a}_{4}$ \\
\hline \multicolumn{7}{|l|}{ Single-trait model } \\
\hline & AUS & $2.46(0.18)$ & $0.35(0.03)$ & $0.13(0.02)$ & $0.08(0.006)$ & $0.05(0.007)$ \\
\hline & CAN & $5.74(0.36)$ & $0.97(0.07)$ & $0.34(0.03)$ & $0.11(0.010)$ & $0.09(0.012)$ \\
\hline & ITA & $5.48(0.37)$ & $0.86(0.07)$ & $0.44(0.03)$ & $0.13(0.014)$ & $0.07(0.011)$ \\
\hline & NZL & $1.46(0.12)$ & $0.40(0.04)$ & $0.15(0.02)$ & $0.08(0.011)$ & $0.07(0.010)$ \\
\hline \multicolumn{7}{|l|}{ Multiple-trait model } \\
\hline & AUS & $3.25(0.26)$ & $0.22(0.04)$ & $0.10(0.01)$ & $0.07(0.010)$ & $0.03(0.005)$ \\
\hline & CAN & $5.10(0.55)$ & $0.68(0.09)$ & $0.28(0.04)$ & $0.14(0.019)$ & $0.06(0.010)$ \\
\hline & ITA & $6.02(0.47)$ & $0.51(0.06)$ & $0.34(0.04)$ & $0.12(0.018)$ & $0.06(0.010)$ \\
\hline & NZL & $1.99(0.14)$ & $0.24(0.03)$ & $0.09(0.01)$ & $0.03(0.005)$ & $0.02(0.004)$ \\
\hline
\end{tabular}

Table 6. Posterior means (SD in parenthesis) of single- and multiple-trait estimates of variances of PE random regression coefficients. Country codes are: AUS $=$ Australia, CAN $=$ Canada, ITA $=$ Italy, NZL $=$ New Zealand.

\begin{tabular}{|c|c|c|c|c|c|c|}
\hline & Country & $\mathrm{a}_{0}$ & $\mathrm{a}_{1}$ & $\mathrm{a}_{2}$ & $\mathrm{a}_{3}$ & $\mathrm{a}_{4}$ \\
\hline \multicolumn{7}{|l|}{ Single-trait model } \\
\hline & AUS & $2.91(0.14)$ & $0.72(0.03)$ & $0.29(0.02)$ & $0.15(0.012)$ & $0.07(0.010)$ \\
\hline & CAN & $6.59(0.27)$ & $0.97(0.06)$ & $0.40(0.03)$ & $0.19(0.017)$ & $0.08(0.013)$ \\
\hline & ITA & $8.03(0.28)$ & $1.33(0.06)$ & $0.50(0.03)$ & $0.29(0.018)$ & $0.16(0.014)$ \\
\hline & NZL & $1.62(0.09)$ & $0.40(0.04)$ & $0.13(0.02)$ & $0.07(0.011)$ & $0.04(0.009)$ \\
\hline \multicolumn{7}{|l|}{ Multiple-trait model } \\
\hline & AUS & $3.13(0.19)$ & $0.80(0.04)$ & $0.33(0.03)$ & $0.19(0.015)$ & $0.14(0.011)$ \\
\hline & CAN & $8.22(0.46)$ & $1.36(0.10)$ & $0.64(0.05)$ & $0.29(0.034)$ & $0.23(0.023)$ \\
\hline & ITA & $9.95(0.40)$ & $1.85(0.08)$ & $0.71(0.05)$ & $0.31(0.028)$ & $0.25(0.022)$ \\
\hline & NZL & $2.20(0.10)$ & $0.63(0.03)$ & $0.26(0.02)$ & $0.15(0.010)$ & $0.11(0.008)$ \\
\hline
\end{tabular}

Table 7. Posterior means (SD in parenthesis) of single-trait estimates of heritabilities (diagonal), genetic (above diagonal), and PE (below diagonal) correlations between regression coefficients, by country. Country codes are: AUS $=$ Australia, CAN $=$ Canada, ITA = Italy, NZL = New Zealand .

\begin{tabular}{|c|c|c|c|c|c|}
\hline Country & $\mathrm{a}_{0}$ & $a_{1}$ & $\mathrm{a}_{2}$ & $\mathrm{a}_{3}$ & $\mathrm{a}_{4}$ \\
\hline \multicolumn{6}{|l|}{ AUS } \\
\hline$a_{0}$ & $0.46(0.03)$ & $-0.27(0.06)$ & $-0.31(0.07)$ & $0.44(0.07)$ & $-0.29(0.08)$ \\
\hline$a_{1}$ & $-0.29(0.03)$ & $0.33(0.03)$ & $-0.05(0.08)$ & $-0.26(0.08)$ & $0.30(0.09)$ \\
\hline $\mathrm{a}_{2}$ & $-0.02(0.04)$ & $-0.10(0.04)$ & $0.31(0.04)$ & $-0.24(0.08)$ & $0.29(0.10)$ \\
\hline$a_{3}$ & $-0.05(0.04)$ & $0.06(0.04)$ & $-0.19(0.04)$ & $0.34(0.04)$ & $-0.38(0.08)$ \\
\hline$a_{4}$ & $0.03(0.05)$ & $-0.03(0.06)$ & $0.13(0.07)$ & $-0.10(0.07)$ & $0.41(0.06)$ \\
\hline \multicolumn{6}{|l|}{ CAN } \\
\hline $\mathrm{a}_{0}$ & $0.47(0.03)$ & $0.23(0.05)$ & $-0.44(0.06)$ & $0.38(0.07)$ & $-0.30 \quad(0.07)$ \\
\hline$a_{1}$ & $-0.07(0.03)$ & $0.50(0.03)$ & $-0.02(0.05)$ & $0.06(0.08)$ & $0.07(0.07)$ \\
\hline $\mathrm{a}_{2}$ & $-0.22(0.04)$ & $0.01(0.04)$ & $0.46(0.04)$ & $-0.56(0.06)$ & $0.53(0.07)$ \\
\hline$a_{3}$ & $0.04(0.04)$ & $-0.12(0.06)$ & $-0.02(0.06)$ & $0.37(0.04)$ & $-0.55(0.07)$ \\
\hline $\mathrm{a}_{4}$ & $-0.09(0.06)$ & $0.08(0.07)$ & $-0.21(0.09)$ & $-0.02(0.09)$ & $0.54(0.06)$ \\
\hline \multicolumn{6}{|l|}{ ITA } \\
\hline $\mathrm{a}_{0}$ & $0.41(0.02)$ & $0.31(0.05)$ & $-0.49(0.05)$ & $0.34(0.06)$ & $-0.35(0.08)$ \\
\hline$a_{1}$ & $-0.00(0.03)$ & $0.39(0.03)$ & $-0.38(0.06)$ & $0.25(0.07)$ & $-0.03(0.09)$ \\
\hline $\mathrm{a}_{2}$ & $-0.19(0.03)$ & $0.12(0.04)$ & $0.47(0.03)$ & $-0.71(0.05)$ & $0.58(0.06)$ \\
\hline$a_{3}$ & $0.12(0.03)$ & $-0.18(0.04)$ & $-0.02(0.05)$ & $0.30(0.03)$ & $-0.57(0.07)$ \\
\hline $\mathrm{a}_{4}$ & $-0.15(0.04)$ & $0.13(0.05)$ & $-0.16(0.06)$ & $-0.07(0.06)$ & $0.31(0.05)$ \\
\hline \multicolumn{6}{|l|}{ NZL } \\
\hline $\mathrm{a}_{0}$ & $0.47(0.03)$ & $-0.32(0.06)$ & $-0.02(0.08)$ & $0.15(0.08)$ & $-0.22(0.07)$ \\
\hline$a_{1}$ & $-0.44(0.04)$ & $0.49(0.05)$ & $0.05(0.09)$ & $0.29(0.08)$ & $0.12(0.10)$ \\
\hline $\mathrm{a}_{2}$ & $0.10(0.07)$ & $-0.11(0.09)$ & $0.54(0.06)$ & $0.02(0.09)$ & $0.40(0.08)$ \\
\hline $\mathrm{a}_{3}$ & $0.07(0.07)$ & $0.21(0.09)$ & $-0.05(0.11)$ & $0.55(0.06)$ & $-0.01 \quad(0.11)$ \\
\hline$a_{4}$ & $-0.09(0.08)$ & $-0.02(0.10)$ & $0.11(0.11)$ & $-0.21(0.11)$ & $0.60(0.06)$ \\
\hline
\end{tabular}


Table 8. Posterior means (SD in parenthesis) of multiple-trait estimates of heritabilities (diagonal), genetic (above diagonal), and PE (below diagonal) correlations between regression coefficients, by country. Country codes are: AUS $=$ Australia, CAN = Canada, ITA = Italy, NZL = New Zealand .

\begin{tabular}{|c|c|c|c|c|c|}
\hline Country & $\mathrm{a}_{0}$ & $\mathrm{a}_{1}$ & $\mathrm{a}_{2}$ & $\mathrm{a}_{3}$ & $\mathrm{a}_{4}$ \\
\hline \multicolumn{6}{|l|}{ AUS } \\
\hline$a_{0}$ & $0.51(0.03)$ & $-0.07(0.08)$ & $-0.47(0.07)$ & $0.45(0.08)$ & $-0.31(0.11)$ \\
\hline$a_{1}$ & $-0.26(0.04)$ & $0.21(0.03)$ & $-0.18(0.09)$ & $0.16(0.10)$ & $-0.20(0.12)$ \\
\hline $\mathrm{a}_{2}$ & $-0.01(0.04)$ & $-0.03(0.04)$ & $0.24(0.03)$ & $-0.39(0.07)$ & $0.43(0.11)$ \\
\hline$a_{3}$ & $0.02(0.05)$ & $-0.10 \quad(0.05)$ & $-0.03(0.06)$ & $0.26(0.04)$ & $-0.57(0.07)$ \\
\hline $\mathrm{a}_{4}$ & $-0.03(0.05)$ & $0.11 \quad(0.05)$ & $0.12(0.05)$ & $-0.09(0.05)$ & $0.20(0.03)$ \\
\hline \multicolumn{6}{|l|}{ CAN } \\
\hline$a_{0}$ & $0.38(0.04)$ & $0.40(0.08)$ & $-0.52(0.08)$ & $0.45(0.09)$ & $-0.21 \quad(0.09)$ \\
\hline$a_{1}$ & $-0.06(0.10)$ & $0.33(0.09)$ & $-0.12(0.11)$ & $0.10(0.11)$ & $0.09(0.12)$ \\
\hline $\mathrm{a}_{2}$ & $-0.20(0.08)$ & $-0.03 \quad(0.09)$ & $0.30(0.08)$ & $-0.54(0.09)$ & $0.18(0.10)$ \\
\hline$a_{3}$ & $-0.02(0.06)$ & $-0.00(0.07)$ & $-0.09(0.08)$ & $0.33(0.05)$ & $-0.49(0.09)$ \\
\hline $\mathrm{a}_{4}$ & $-0.18(0.05)$ & $-0.02(0.07)$ & $0.09(0.07)$ & $-0.01(0.08)$ & $0.22(0.03)$ \\
\hline \multicolumn{6}{|l|}{ ITA } \\
\hline$a_{0}$ & $0.38(0.03)$ & $0.45(0.07)$ & $-0.63(0.05)$ & $0.41(0.08)$ & $-0.41 \quad(0.10)$ \\
\hline$a_{1}$ & $-0.04 \quad(0.03)$ & $0.22(0.02)$ & $-0.36(0.09)$ & $0.31(0.08)$ & $-0.17(0.09)$ \\
\hline$a_{2}$ & $-0.16(0.04)$ & $0.06(0.04)$ & $0.32(0.04)$ & $-0.65(0.06)$ & $0.55(0.09)$ \\
\hline$a_{3}$ & $0.09(0.04)$ & $-0.13(0.05)$ & $-0.09(0.06)$ & $0.27(0.04)$ & $-0.53(0.08)$ \\
\hline$a_{4}$ & $-0.16(0.04)$ & $0.12(0.05)$ & $-0.08(0.06)$ & $-0.12(0.06)$ & $0.20(0.03)$ \\
\hline \multicolumn{6}{|l|}{ NZL } \\
\hline$a_{0}$ & $0.47(0.03)$ & $-0.16(0.07)$ & $0.01(0.08)$ & $0.32(0.09)$ & $-0.36(0.07)$ \\
\hline$a_{1}$ & $-0.40(0.04)$ & $0.28(0.03)$ & $0.02(0.11)$ & $0.04(0.10)$ & $0.10(0.10)$ \\
\hline $\mathrm{a}_{2}$ & $-0.03(0.04)$ & $-0.05(0.04)$ & $0.26(0.03)$ & $-0.18(0.10)$ & $0.26(0.11)$ \\
\hline$a_{3}$ & $0.19(0.04)$ & $0.00(0.05)$ & $-0.01 \quad(0.05)$ & $0.16(0.03)$ & $-0.21 \quad(0.13)$ \\
\hline$a_{4}$ & $-0.19(0.04)$ & $0.16(0.04)$ & $0.13(0.05)$ & $-0.08(0.05)$ & $0.16(0.03)$ \\
\hline
\end{tabular}

Posterior means of multiple-trait estimates of genetic correlations between countries for the same lactation curve coefficients are shown in Table 9. Correlations ranged from 0.83 (intercept between Australia and New Zealand) to 0.03 (quadratic term between Italy and New Zealand). The largest values of correlations were for the intercept; the smallest value of 0.66 between Italy and New Zealand. Correlations for the constant term were equivalent to correlations between total yields in lactation. The linear term had the lowest correlation between Italy and New Zealand, followed by Canada and New Zealand. Canada and Italy showed the highest genetic correlation for this component. Posterior SD were from 0.03 to 0.05 for $\mathrm{a}_{0}$, and from 0.08 to 0.1 for $\mathrm{a}_{1}$, indicating lower precision of the linear term estimates.

\section{Eigenvalues of Covariance Matrices}

Eigenvalues of single-trait genetic and PE covariance matrices are shown in Table 10. Plots of eigenfunctions are shown in Figures 6 through 9 for genetic covariance matrix. The first two eigenvalues accounted for $\sim 90 \%$ of the genetic variance in TD yields for all countries. Corresponding eigenfunctions described an overall level of production during lactation, and a persistency component, acting differently in early and late parts of lactation. Differences between countries were small with respect to principal component analyses of the genetic covariance matrices. Slightly higher persistency component could be noticed for New Zealand (17\% vs. up to $13 \%$ for other countries). The PE eigenvalues and eigenfunctions (not presented) showed similar properties. Matrices of eigenvectors for both genetic and PE components (not shown) had a structure close to diagonal, with the most weights associated with the corresponding original variables in Legendre polynomials. This would indicate that, without loss of accuracy, $\mathrm{a}_{0}$ and $\mathrm{a}_{1}$ could be interpreted as a measure of total yield and persistency of lactation, respectively.

Table 9. Posterior means (SD in parenthesis) of multiple-trait estimates of between countries, genetic correlations for random regression coefficients. Country codes are: AUS = Australia, CAN = Canada, ITA = Italy, NZL = New Zealand.

\begin{tabular}{lllllll}
\hline & AUS-CAN & AUS-ITA & AUS-NZL & CAN-ITA & CAN-NZL & ITA-NZL \\
\hline $\mathrm{a}_{0}$ & $0.79(0.04)$ & $0.74(0.04)$ & $0.83(0.03)$ & $0.77(0.04)$ & $0.72(0.04)$ & $0.66(0.05)$ \\
$\mathrm{a}_{1}$ & $0.43(0.09)$ & $0.42(0.09)$ & $0.39(0.08)$ & $0.55(0.08)$ & $0.28(0.10)$ & $0.16(0.08)$ \\
$\mathrm{a}_{2}$ & $0.61(0.08)$ & $0.59(0.07)$ & $0.23(0.11)$ & $0.59(0.09)$ & $0.21(0.11)$ & $0.03(0.11)$ \\
$\mathrm{a}_{3}$ & $0.52(0.06)$ & $0.47(0.09)$ & $0.43(0.11)$ & $0.46(0.09)$ & $0.44(0.11)$ & $0.50(0.10)$ \\
$\mathrm{a}_{4}$ & $0.35(0.12)$ & $0.46(0.09)$ & $0.21(0.12)$ & $0.37(0.12)$ & $0.17(0.12)$ & $0.27(0.12)$ \\
\hline
\end{tabular}


Table 10. Eigenvalues (EIG) and relative proportions (PROP) for the genetic covariance matrix from the single-trait model, by country. Country codes are: AUS = Australia, CAN = Canada, ITA = Italy, NZL = New Zealand.

\begin{tabular}{|c|c|c|c|c|c|c|c|c|c|}
\hline \multirow{2}{*}{ Item } & & \multicolumn{2}{|c|}{ AUS } & \multicolumn{2}{|c|}{ CAN } & \multicolumn{2}{|c|}{ ITA } & \multicolumn{2}{|c|}{ NZL } \\
\hline & & EIG & PROP & EIG & PROP & EIG & PROP & EIG & PROP \\
\hline \multirow[t]{5}{*}{ Genetic } & 1 & 2.52 & 0.82 & 5.90 & 0.81 & 5.71 & 0.82 & 1.51 & 0.70 \\
\hline & 2 & 0.33 & 0.11 & 0.90 & 0.13 & 0.80 & 0.12 & 0.36 & 0.17 \\
\hline & 3 & 0.13 & 0.04 & 0.32 & 0.04 & 0.36 & 0.05 & 0.17 & 0.08 \\
\hline & 4 & 0.06 & 0.02 & 0.08 & 0.01 & 0.06 & 0.01 & 0.07 & 0.03 \\
\hline & 5 & 0.04 & 0.01 & 0.05 & 0.01 & 0.03 & 0.01 & 0.05 & 0.02 \\
\hline \multirow[t]{5}{*}{$\mathrm{PE}$} & 1 & 2.99 & 0.72 & 6.61 & 0.80 & 8.05 & 0.78 & 1.72 & 0.76 \\
\hline & 2 & 0.65 & 0.16 & 0.97 & 0.12 & 1.36 & 0.13 & 0.32 & 0.14 \\
\hline & 3 & 0.30 & 0.07 & 0.39 & 0.05 & 0.48 & 0.05 & 0.13 & 0.06 \\
\hline & 4 & 0.14 & 0.03 & 0.19 & 0.02 & 0.27 & 0.03 & 0.06 & 0.03 \\
\hline & 5 & 0.07 & 0.02 & 0.07 & 0.01 & 0.14 & 0.01 & 0.04 & 0.02 \\
\hline
\end{tabular}

The first four principal components of the genetic multiple-trait covariance matrix explained more than $90 \%$ of the total genetic variance, with the largest component at $73 \%$ contribution. Overall, across-country level of production could be easily identified in the leading eigenvector, with weights of $0.43,0.56,0.60$, and 0.31 for Australia, Canada, Italy, and New Zealand, respectively. Remaining principal components were not easy to interpret. They had, however, the largest weights on level of production and persistency components.

\section{DISCUSSION}

International evaluation of dairy sires using performance records could be the next step in the development of across-country comparison methods (Weigel et al., 2001). Test-day models are becoming more popular for within-country genetic evaluation. Random regression

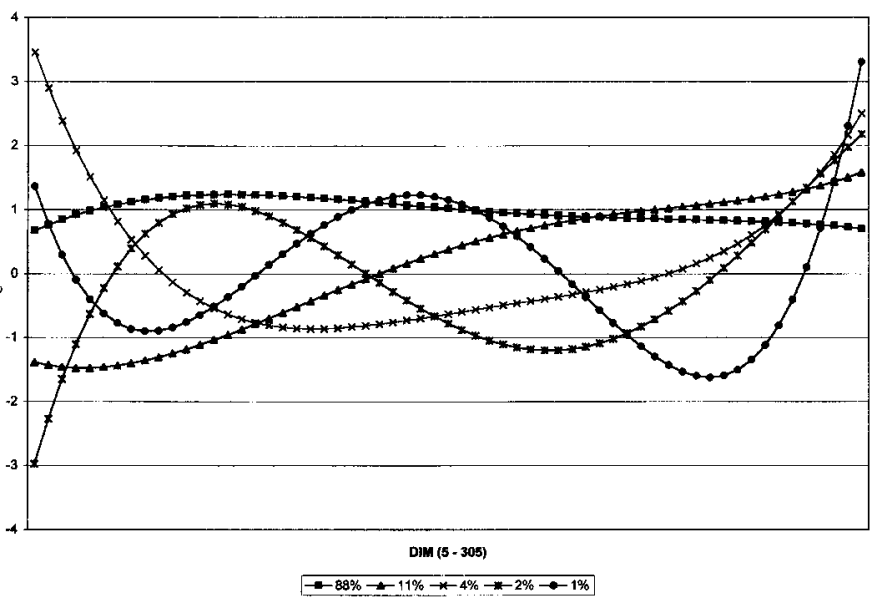

Figure 6. Eigenfunctions of genetic covariance matrix for Australia estimated from single-trait model. models give tremendous opportunity for analysis of all aspects of lactation curves, including total yield and persistency and differences in average length of lactation. Current computational restraints for random regression models should become less problematic in the near future due to technological progress in computer hardware.

The current study was the first attempt to apply a random regression TD model in a multi-country scenario. Several simplifying assumptions were made to facilitate computations. The same models were used for each of four participating countries. This could be a subject for improvement, allowing for specific withincountry effects in the model. Estimation of across-country covariances required a subset of the data to be used, which further reduced opportunities for a correct modeling (e.g., small number of observations for certain levels of fixed effects). Both genetic and PE regressions were modeled by the same general function (fourth-

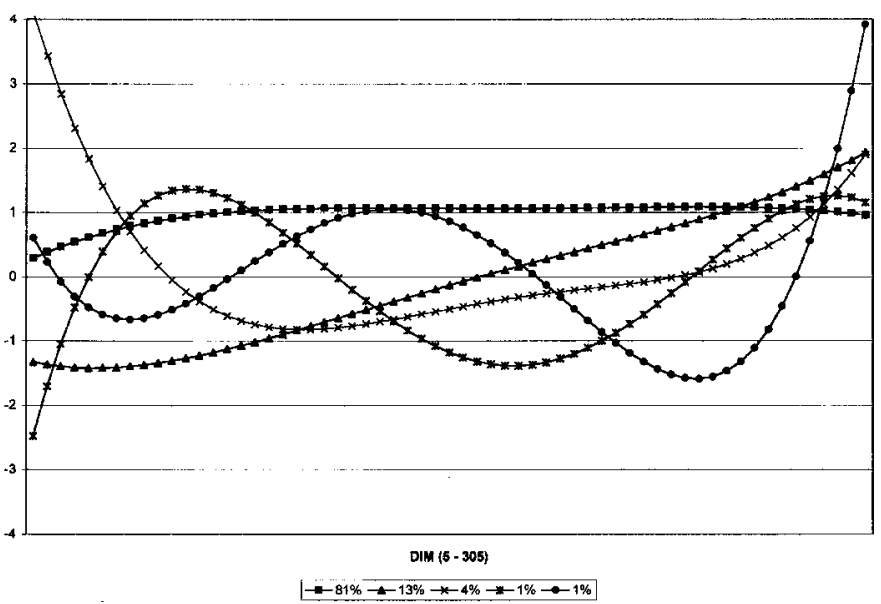

Figure 7. Eigenfunctions of genetic covariance matrix for Canada estimated from single-trait model. 


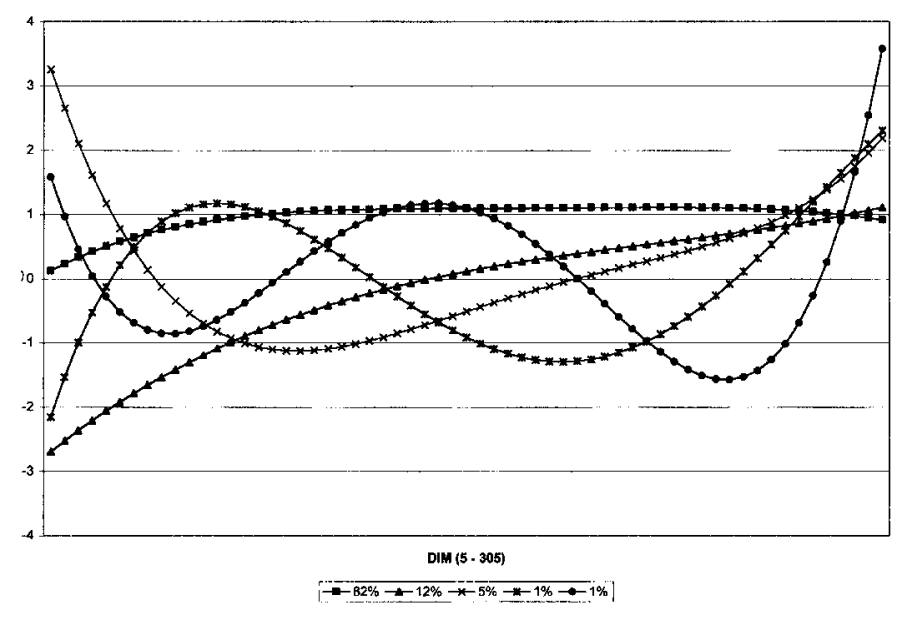

Figure 8. Eigenfunctions of genetic covariance matrix for Italy estimated from single-trait model.

order Legendre polynomials) for each country, and a maximum lactation length of $305 \mathrm{~d}$ was assumed. Finally, only one trait (i.e., milk yield in first lactation) was analyzed.

Comparison of single-trait estimates of variance components indicated that both genetic and environmental variation in lactation curve parameters differed between countries. This relates to the absolute value of estimates and also to the relationships between different parameters for a given country. One set of singletrait genetic and PE covariance matrices (even up to the scaling factors) cannot be used to model variation of regression coefficients for all four countries. The pattern of variation in TD milk yields, in terms of principal components, showed more similarity between countries. Two major principal components (total yield in

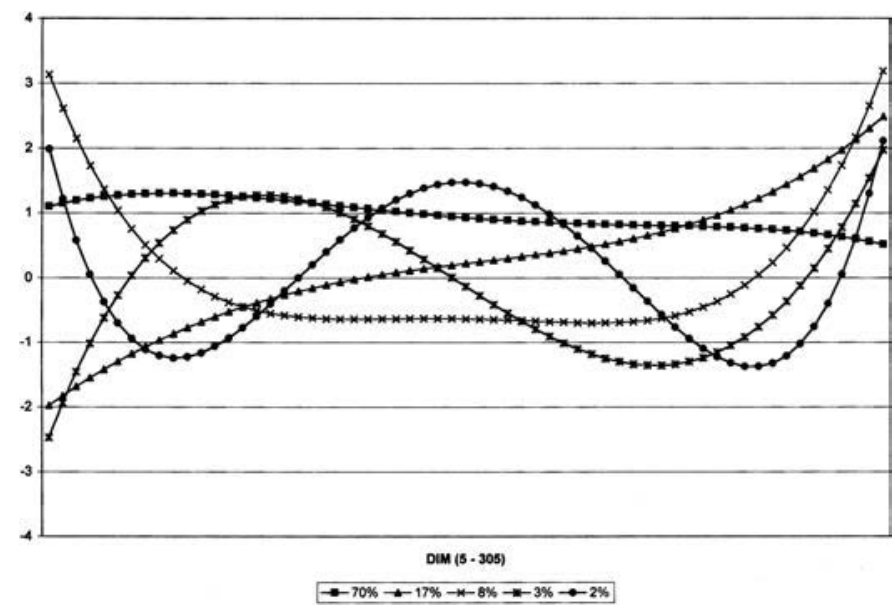

Figure 9. Eigenfunctions of genetic covariance matrix for New Zealand estimated from single-trait model. lactation and persistency) were very consistent across countries.

Parameter estimation with multiple-country model was shown to be highly dependent on the quantity and quality of genetic ties between countries (Sigurdsson et al., 1996). An animal model was applied in this study that did not provide direct genetic links between countries (no cow had TD records in more than one country). All genetic ties were realized through sires with daughters in multiple countries. Selection of appropriate subsets of data for parameter estimation must balance data size and genetic connections.

Estimates of genetic correlations for the total yield in lactation between four analyzed countries were, in general, lower than reported elsewhere (Carabano et al., 1989; Stanton et al., 1991; Cienfuegos-Rivas et al., 1999; Weigel et al., 2001). Genetic correlations estimated by Weigel et al. (2001) with sire model- and daughter-performance milk records were: 0.82 (Australia and Canada), 0.84 (Australia and Italy), 0.96 (Australia and New Zealand), 0.94 (Canada and Italy), 0.89 (Canada and New Zealand), and 0.85 (Italy and New Zealand). These estimates were slightly larger than parameters currently used in INTERBULL international sire comparisons. Estimates of genetic correlations obtained in this study were higher, however, than corresponding correlations between sire's (with at least 20 daughters) EBV estimated using single-trait models and all data from each country (results not shown). Correlation coefficients $<0.8$ give an indication of the existence of genotype $\times$ environment interaction (Robertson, 1959). Results of this study indicated genotype $\times$ country interaction for parameters of the shape of lactation curve, especially between New Zealand and countries with intense management systems for the total yield of milk in lactation, and all four countries for lactation persistency. Peterson (1991) reported evidence for genotype $\times$ environment interaction in milk yield between environments and sires within strains for Canada and New Zealand Holsteins.

Reasons for low values of estimates of between country genetic correlations obtained in this study might be the real differences in the genetics of lactation curve parameters between environments (countries). Lack of sufficient genetic ties might also contribute to possible underestimation of genetic correlations. Further studies are needed.

\section{ACKNOWLEDGMENTS}

Data were provided by the genetic evaluation centers of Australia, Canada, Italy, and New Zealand, and by INTERBULL Center, Uppsala, Sweden. The authors are grateful to the Ontario Ministry of Agriculture, 
Food and Rural Affairs, DairyGen, and the Natural Science and Engineering Research Council for their financial support.

\section{REFERENCES}

Carabano, M. J., L. D. Van Vleck, G. R. Wiggans, and R. Alenda. 1989. Estimation of genetic parameters for milk and fat yields of dairy cattle in Spain and the United States. J. Dairy Sci. 72:3013-3022.

Cienfuegos-Rivas, E. G., P. A. Oltenacu, R. W. Blake, S. J. Schwager, H. Castillo-Juarez, and F. J. Ruiz. 1999. Interaction between milk yield of Holstein cows in Mexico and the United States. J. Dairy Sci. 82:2218-2223.

INTERBULL Bulletin No. 24. 2000. National genetic evaluation programs for dairy production traits practiced in Interbull member countries 1999-2000. Interbull Center, Uppsala, Sweden.

Kistemaker, G. J. 1997. The comparison of random regression testday models and a 305-d model for evaluation of milk yield in dairy cattle. Ph.D. thesis. University of Guelph.
Peterson, R. G. 1991. Evidence of a G×E with Canadian and New Zealand Holsteins. EAAP Mtg. Berlin, September 1991.

Robertson, A. 1959. The sampling variance of the genetic correlation coefficient. Biometrics 15:469-485.

Schaeffer, L. R. 1994. Multiple-country comparison of dairy sires. J. Dairy Sci. 77:2671-2678.

Sigurdsson, A., G. Banos, and J. Philipsson. 1996. Estimation of genetic (co)variance components for international evaluation of dairy bulls. Acta Agric. Scand. 46:129-136.

Stanton, T. L., R. W. Blake, R. L. Quaas, L. D. Van Vleck, and M. J. Carabano. 1991. Genotype by environment interaction for Holstein milk yield in Colombia, Mexico, and Puerto Rico. J. Dairy Sci. 74:1700-1714.

Weigel, K. A., R. Rekaya, N. R. Zwald, and W. F. Fikse. 2001. International genetic evaluation of dairy sires using a multiple-trait model with individual animal performance records. J. Dairy Sci. 84:2789-2795.

Zwald, N. R., K. A. Weigel, W. F. Fikse, and R. Rekaya. 2001. Characterization of dairy production systems in countries that participate in the international bull evaluation service. J. Dairy Sci. 84: $2530-2534$. 